\title{
Child Maintenance, Father Child Relationships and Family Wellbeing
}

\author{
Paulette Andrea Henry \\ Department of Sociology, University of Guyana \\ 95 Amsville Housing Scheme, New Amsterdam, Berbice, Guyana \\ Tel: 592-650-7855/333-2097 E-mail: phenryugbc@yahoo.com
}

Received: May 14, 2015 Accepted: June 12, 2015 Published: October 4, 2015

doi:10.5296/iss.v3i2.7693 URL: http://dx.doi.org/10.5296/iss.v3i2.7693

\begin{abstract}
This study assesses the correlation between the provision of child maintenance and father child relationship which ultimately affects child wellbeing. Using a mixed method approach, court records were examined over a five year period and interviews with thirty fathers were conducted. The data reveal that the majority of fathers were in non-marital relationships, pointing to the vulnerability of children born within such unions especially when family finances are scarce. Perceptions on the father child relationship were sought from fathers on their relationship with their children. The study found that fathers understood their financial responsibilities to their children and yearned for improved relationships with their offspring but their economic situation, relationships with the mother of the child, geographic proximity, family of origin and the court system hindered these relationships. Options to consider when fathers cannot meet their financial commitment have been proposed.
\end{abstract}

Keywords: child maintenance, father child relationship, child well being 


\section{Introduction}

The father - child relationship is often perceived as an integral part of the child's overall well being. However family breakdown may lead to different variations in the roles of fathers in the lives of their children. This may be due to father and mothers forming new relationships and also new families which can impact the relationships fathers have with their child or children in homes where they are no longer seen as having an active presence. This lack of a meaningful relationship with their father has the potential to disrupt child well being which is closely tied to their lives within their family (Wollny, Apps and Henricson, 2010).

Traditional roles of fatherhood have been tied to that of protector and provider, thus when the father is absent, two essential elements are missing. First, as the protector he is not there to cushion the child from the shocks of growing up and second as the provider, he performs an economic function in ensuring that the child's needs are met. Tanfer and Mott (1997) posit that in the traditional model of fatherhood, fathers played a dominant role in the lives of their children, assuming a broad range of responsibilities in defining and supervising the children's development. Domestic control was largely in the hands of men; wives were expected to defer to husbands on matters of childrearing. A father's moral role persisted through childhood into adult life. His influence was pervasive and usually exceeded the mother's responsibilities over the child (Rotundo, 1985). In the beginning of the nineteenth century, with the shift away from an agrarian to an industrial mode of production, the paternal control over children began to erode. As men's economic roles increasingly drew them outside the home and into the market place, women extended their sphere of domestic influence (Filene, 1986; Lasch, 1977). An increase of affective ties within the family reshaped the nature of parenthood and parent-child relations (Shorter 1975; Stone, 1979). The change in the family and parental division of labor was the beginning of a shift in the balance of power within the family. Tanfer and Mott (1997) further assert that the spatial separation of work and home helped revise marital and parental roles. For fathers, this was the beginning of an almost exclusive emphasis on economic responsibilities, which naturally, curtailed the men's day-to-day contact with their children.

The terms child maintenance and child support will be used interchangeably in this study. The legal terminology refers to child maintenance, but in local (Guyanese) parlance when speaking to fathers the term "child support" is well recognized as the father providing for the child through the legal mechanisms. Child maintenance allows the father to upkeep his provider role which is important to the economic well-being of the child. However, child maintenance must not only be perceived from a purely economic standpoint, rather a father must be viewed as an integral stakeholder in the overall care and development of the child. The father-child relationship therefore needs to be recognized as important from both a financial as well as a psychosocial perspective as both are important to the child's well being. Wellbeing according to Statham and Chase (2010) is generally understood as the quality of people's lives. It is a dynamic state that is enhanced when people can fulfill their personal and social goals. It is understood both in relation to objective measures, such as household income, educational resources and health status; and subjective indicators such as happiness, perceptions of quality of life and life satisfaction. 


\subsection{Primary Objective}

The primary objective of this research is to ascertain fathers' perception on child maintenance, their relationship with their child and its effect on child and family wellbeing.

Thus the critical questions that will inform this study are:

- How has child maintenance improved the father child relationship and overall well being of the child?

- What additional factors mitigate father child relationship and impact child and family wellbeing?

- What social security measures can be put in place when fathers cannot pay thereby contributing to the reduction in child poverty and improving child wellbeing?

\subsection{Scope of the Study}

This research presents the findings from fathers who pay child maintenance through the courts at two courts in Guyana. It shares their perceptions of the quality of relationships with their children and its contribution to family wellbeing. It is hoped that the data can be instructive to policy makers working on child rights and child protection and that this study can set the stage to inform how an arrangement that is in the best interest of the child can be instituted to allow non-custodial fathers more time with their children since fathers are integral to the child's growing up and overall well being.

This study provides an opportunity for men and agencies working with men to understand how the family within which the child is located becomes even poorer due to lack of the father's economic and psychosocial support. It also suggests that where women are unable to secure child maintenance from fathers due to failure to locate them, or their inability to pay, interim social security measures should be provided for child support until the father is able to undertake his responsibility, thereby reducing the burden of child care on women. Global data shows that women continue to hold a significant presence amongst the world's poor mostly in developing countries (UN Women Watch). This may be further underscored when child care is considered. Care of children and household responsibilities fall in large part on women with deleterious effects on their working lives (OECD, 2008). Thus, if fathers do not maintain their children and if there are no social security measures when fathers do not or cannot pay, then obviously women and children will continue to suffer. Importantly, the study sought to get the opinions of fathers on their parenting role which includes the economic and social wellbeing of their child, and how they felt when they are unable to meet those roles. Whilst this study is limited to fathers, it is anticipated that further study would also seek to garner inputs from mothers and children.

\section{What the Literature Says?}

\subsection{Child Maintenance and the Court}

Several writers have expounded on the relationship which exists between fathers who are mandated to pay support for their children via the court. Child support is among the most 
important obligations of out-of-home fathers to their children, and provision of adequate support is central to a child's economic well-being (Ross, 1994). In Australia, the Australian Department of Government has derived a formula which determines how child support should be paid taking into account the varied family forms and circumstances. Noting the stringent mechanisms enforced by countries to get fathers to pay, the views of fathers were garnered in several pieces of literature. Two key points that emanated from the writings of Thomson (1994) was the view that fathers question the increasing coerciveness of child support enforcement procedures without equally helpful avenues to ensure that their visitation privileges are not undermined or restricted by a former spouse.

It has been found that children strongly miss the absent father who does not visit long after he has ceased to be part of their everyday experience (Thomson, 1994). Children benefit when their mothers and fathers can cooperate satisfactorily on their behalf regarding issues of visitation, financial support, health care, educational costs, and other concerns that affect their well-being. Children suffer significant economic disadvantages from a father's failure to provide adequate child support and, conversely, gain from his reliable financial commitment to them (Ross, 1994). On the other hand, an important concern stressed by mothers is that child support payments have remained small even when mothers have been awarded of full custody. By many estimates, the total amount of child support awarded a mother is inadequate to the true costs of raising children. Moreover, even when payments are received, they are often partial or inadequate (Thomson, 1994).

\subsection{Issues for Child Well Being}

It is important that an understanding of child maintenance, father child relationship and child well being be discussed. Well being is described as a dynamic process in which a child's external circumstances, socioeconomic background, physical surroundings are constantly interacting with their individual characteristics to satisfy their needs and thus build psychological resources, capabilities and positive interactions with those around them (NEF, 2009). Furthering this discussion, Camfield et al (2008) asserts that children's well being represents a large proportion of the population in developing countries where well being is a major research and policy concern. Well being for children is not homogeneous and reflects the unique experiences of children. In view of this, well being must be considered under the United Nations Convention on the Rights of the Child (UNCRC) best interest of the child principles. The authors went on to state that definitions of well being must recognize children as active agents with distinctive perspectives and experiences (and cultures) who play important roles in their households and societies in shaping their lives and negotiating their well being. It is within this context of well being and children's relationships with their fathers who maintain them via the legal system will be examined.

A child's economic circumstance is critical to child well being. Hence there is an extremely close correlation between child maintenance and child and family economic situation, so that when a father does not pay, the predominantly female headed family sinks deeper into the mire of poverty affecting child and family well being. According to Bradshaw et al (2006), the quality of relationships and children's personal well being component is often missing 
from discourses on child well being. Further, conclusions drawn from a research by Bartfe ld et al (2000) for the Organization for Economic Development (OECD) which examined the current and potential role of child support in altering the economic well-being of custodial and noncustodial families after marital dissolution indicated that custodial mothers and children fare dramatically worse than noncustodial fathers. Divorcing mothers, generally receive more support than unmarried mothers and indicate that child support, despite all its imperfections, is important in improving the well-being of custodial mothers and children.

According to Statham and Chase (2000), there is some emerging consensus that childhood well being is multi-dimensional, should include dimensions of physical, emotional and social wellbeing; should focus on the immediate lives of children but also consider their future lives; and should incorporate some subjective as well as objective measures. Moreover, the authors assert that international comparisons indicate that wellbeing is negatively associated with income inequality and positively associated with spending on family benefits and services. However, whilst the authors posit that there is no direct association between poor childhood wellbeing and the prevalence of 'broken families', they assert that there is a close association between childhood wellbeing and positive family relationships. Guyana, for example, has a large child population since more than 70 percent of its populace are under age 18 with children within the $0-15$ age cohort accounting for more than a third of Guyana's population (36.4 percent). Children not only make up a significant portion of Guyana's population, but are also a significant proportion of Guyana's poor. (UNICEF Guyana draft report, 2014) Child poverty impacts child well being and it is therefore likely to be exacerbated where custodial mothers are forced to depend on child maintenance.

\subsection{Father Involvement/Visitation and Child Maintenance}

Important to this study is the trend of causality guiding similar research in that it has been found by Arditti and Timothy (1993) that greater father-child contact is believed to facilitate greater financial responsibility by fathers. It is felt however that when the traditional roles of fatherhood changed, this may have absolved fathers from some of their responsibilities. Fanfar and Mott (1997) suggest that married men have internalized the "full participation" paradigm, so that when they divorce and typically are expected or able to fulfill only the "good provider" role, resentment sets in. This, then, can lead to total rejection of all roles (i.e., "If I can't have the fun part of the father role, then I don't want any"). Evidence for the flight from commitment and responsibility is provided by the decline in the marriage rate and the rise in the divorce rate. The parallel rise in cohabitation also reflects men's and women's unwillingness to commit to and support a traditional family.

While there is a fairly common belief that men do not pay child support because of insufficient enforcement, the more realistic and intractable problem may well be that there is a very loose psychological attachment between noncustodial fathers and their children. Seltzer (1991) cited studies of non-resident fathers' relationships with their children suggesting that many fathers handle the pain of trying to maintain close bonds after separation by limiting their contact with children (Hetherington, Cox, and Cox, 1978; Lund, 1987). By avoiding contact, some fathers face fewer reminders of their "lost" children. Other 
non-resident fathers limit their contact with children to avoid conflict with the former spouse (Wright and Price, 1986). Still other fathers gradually drift away from their children, remarry, and establish new families that compete for their time, attention, and income (Hetherington and Camara, 1984; Wallerstein and Huntington, 1983). Statistics on the amount of contact between noncustodial fathers and their children is alarmingly low, particularly after a lengthy separation (Mott, 1983; Furstenberg, 1991; Marsiglio, 1998).

The provision of child support is therefore closely related to the amount of contact with the children, which in turn is strongly associated with men's socioeconomic position (Seltzer, Schaeffer, and Charng, 1989). Significantly, and surprisingly, support and contact figures for never married fathers appear to be as high as the figures for men who were once wed to the mothers. If these figures continue to hold, then there is not much advantage gained by the children of non-custodial fathers for having been born in wedlock (Tanfer and Mott, 1997). Not dissimilarly, Arditti and Keith (1993) suggest that the data between visiting and paying is inconclusive. Rather the authors have pointed to other important variables such as fathers' economic status, father satisfaction with the custody arrangement, having a good relationship with child's mother, proximity of father living arrangements in relation to children, and quality of the relationship prior to separation, as criticaldeterminants in the payment of child support.

\subsection{The Guyana Legislation}

According to Mc Dowel (2000), there are a number of variations as it relates to child maintenance in the commonwealth countries. In some countries such as Guyana and Trinidad, the parent in question has to pay support based on wages. This mandates that the person must take their pay slip to the court. The age of child maintenance ranges from country to country, some until the age of 16 or 18 . However, if the child is in school or ill, payments could be extended further. In Guyana when a person is brought before the magistrate court it is up to the magistrate to make the decision as to how much money that parent pays. Failure to pay child maintenance can result in the individual being incarcerated.

According to the laws of Guyana, persons who have children have a duty to maintain their child regardless of their marital status. Guyana repealed old legislations covering child maintenance to remove the discrimination to children born out of wedlock. However although new legislations have been introduced, namely the Custody, Contact, Guardianship and Maintenance Act No.5 of 2011 enacted in 2011 and the Domestic Violence Act of 1996, there still appears to be some discrepancies with its utility by the Court up till 2014. The court records reveal that the same old forms are still being used and the old legislations are still being presented.

More importantly however both the old and new legislation address the need for persons who have parental rights to provide maintenance or money for the welfare of their children. Parental rights embody a person whose responsibility is to take care of that child as long as the child is treated as a part of the family. According to the Law and You (2003), a child has the right to be maintained by both parents whether s/he is born in or out of wedlock The father of a child born out of wedlock is the man whom a court has adjudged to be the father 
or the man who has acknowledged the child as his and has contributed to the child's maintenance. Child support orders provide the formal structure for the sharing of child-related costs after divorce or separation. Perhaps because child support has the potential to alter economic outcomes, many observers fault the child support system for the persis tence of negative outcomes experienced by mothers and children. Little research, however, has attempted to quantify the role that child support does or could play (Bartfield, 2000). Thus there continues to be mixed views. Seltzer (1991) suggests that legislative attempts to ameliorate the negative effects of parental separation on children focus on more rigorous enforcement of child support obligations. It is further surmised that to improve the economic welfare of children, encouraging non-resident parents to pay child support may affect other aspects of relationships between parents and children who live apart.

\section{Methodological Approach}

This research utilizes both quantitative and qualitative approaches. The data on child maintenance was examined over a five year period, 2008 - 2013 from persons who sought recompense at two magistrate courts in Guyana. Data collection tools included document studies, key informant interviews with fathers and two magistrates.

Using focus interviews, the views of thirty (30) fathers were garnered to solicit their perceptions on child maintenance and its impact on their relationship with their child. Fathers were randomly selected over a two day period as they entered to pay their child support at a rural and urban magistrate court. The responses were analyzed and informed the findings. The opinions of the two magistrates were also documented.

\subsection{Interview Protocol}

Each interview lasted approximately fifteen minutes. All participants were informed about the reason for the research and confidentiality procedures. Participants were thanked for sharing their information.

\subsection{Ethical Considerations}

The researcher observed all ethical protocols in the conduct of this study. The participants were all informed of the purpose of the research and their approval sought prior to its conduct. Further, all of the respondents who voluntarily participated in the study were assured of both anonymity and confidentiality.

\section{The Findings and Discussions}

\subsection{Demographic Data}

The demographic data show that 70 percent of the fathers summoned (21) for child maintenance were between ages 25 to 45 with 10 percent (3) being over age 55 with the remainder (20 percent) being young fathers under the age of 25 . Just over 50 percent of the fathers (16) participating in the study were supporting one child with 9 or 30 percent supporting up to three children and the others(20 per cent) supporting even more than three children. Only 4 of the study participants (13.3 percent) were married to the mother of their 


\section{Macrothink}

children.

\subsection{Longitudinal Data}

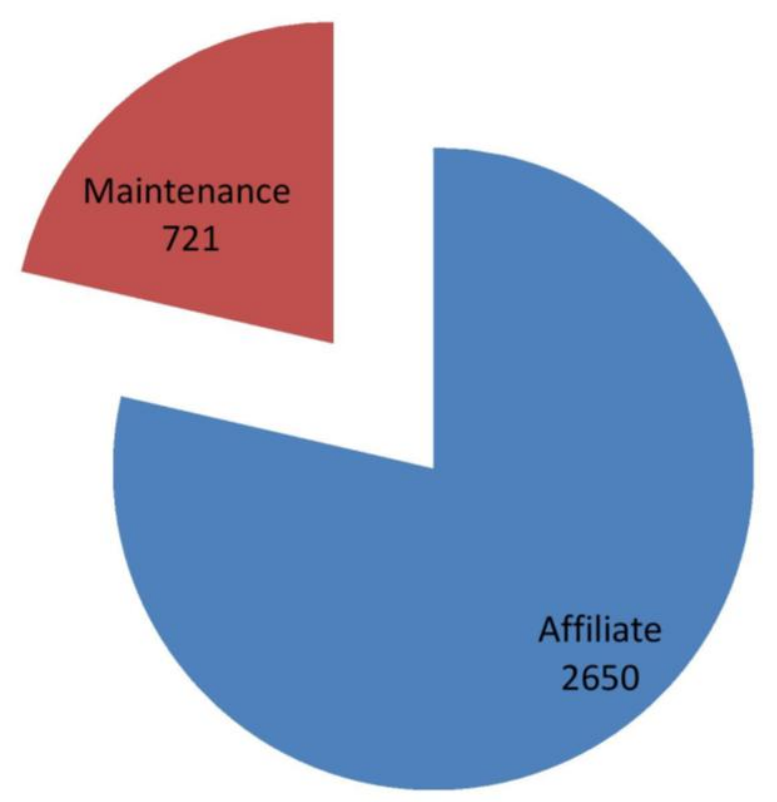

Figure 1. Total child maintenance cases before courts in two districts 2009-2013

Source: Data extracted from Court Records of two Magistrate Courts in Berbice Guyana

An analysis of court record s between 2009 and 2013 shows that 3371 cases were before the court for maintenance in two districts. Fathers who did not have a marital relationship with their child's mother consistently outnumbered fathers in the Court for the payment of child support, 2650 or 78.6 percent whereas only 721 or 21.3 percent of the fathers who were once married had been summoned for maintenance (Figure 1).

What is instructive is that the large majority of fathers summoned for child maintenance were from affiliate or non-marital relationships as shown in Figure 1. The findings may suggest that coercive measures had to be used to get fathers from non-marital unions to honour their financial obligation to their children. Notably, these findings are very similar to the findings of Seltzer, Schaeffer, and Charng (1989) suggesting that fathers who were married probably had a stronger sense of commitment to their child based on relationships already established. The foregoing also points to a greater vulnerability experienced by children born outside of non marital unions and the situation in Guyana is not dissimilar to the findings of Tanfer and Mott (1997) whose study in the United States of America also showed low levels in child maintenance for children from non-marital unions. It could be assumed that it was the non-support for their children that influenced the mothers of the children to seek redress through the legal system. 


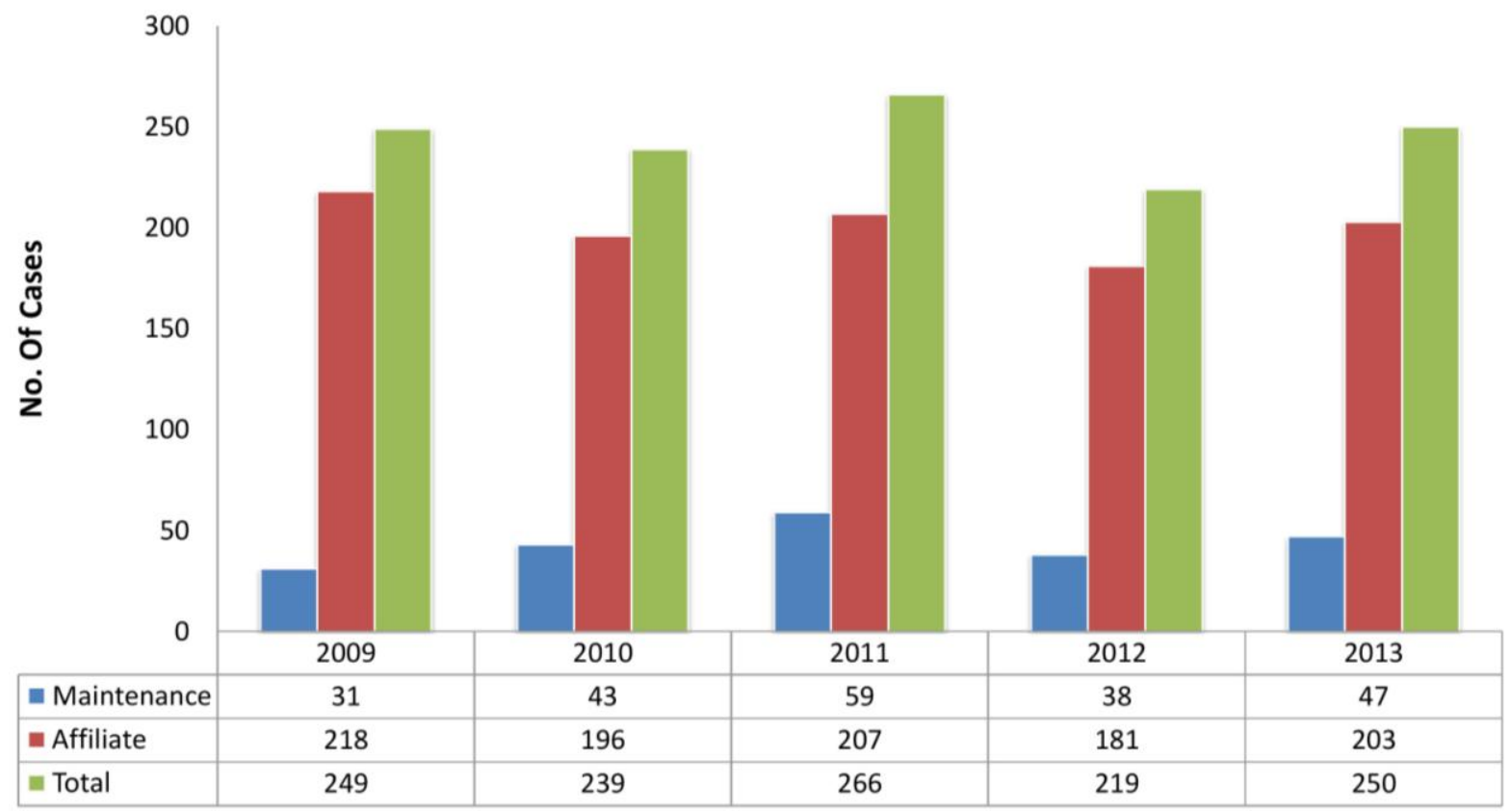

Figure 2. Rural child maintenance cases (whim magistrate court) 2009-2013

Source: Data extracted from Court Records, 2014

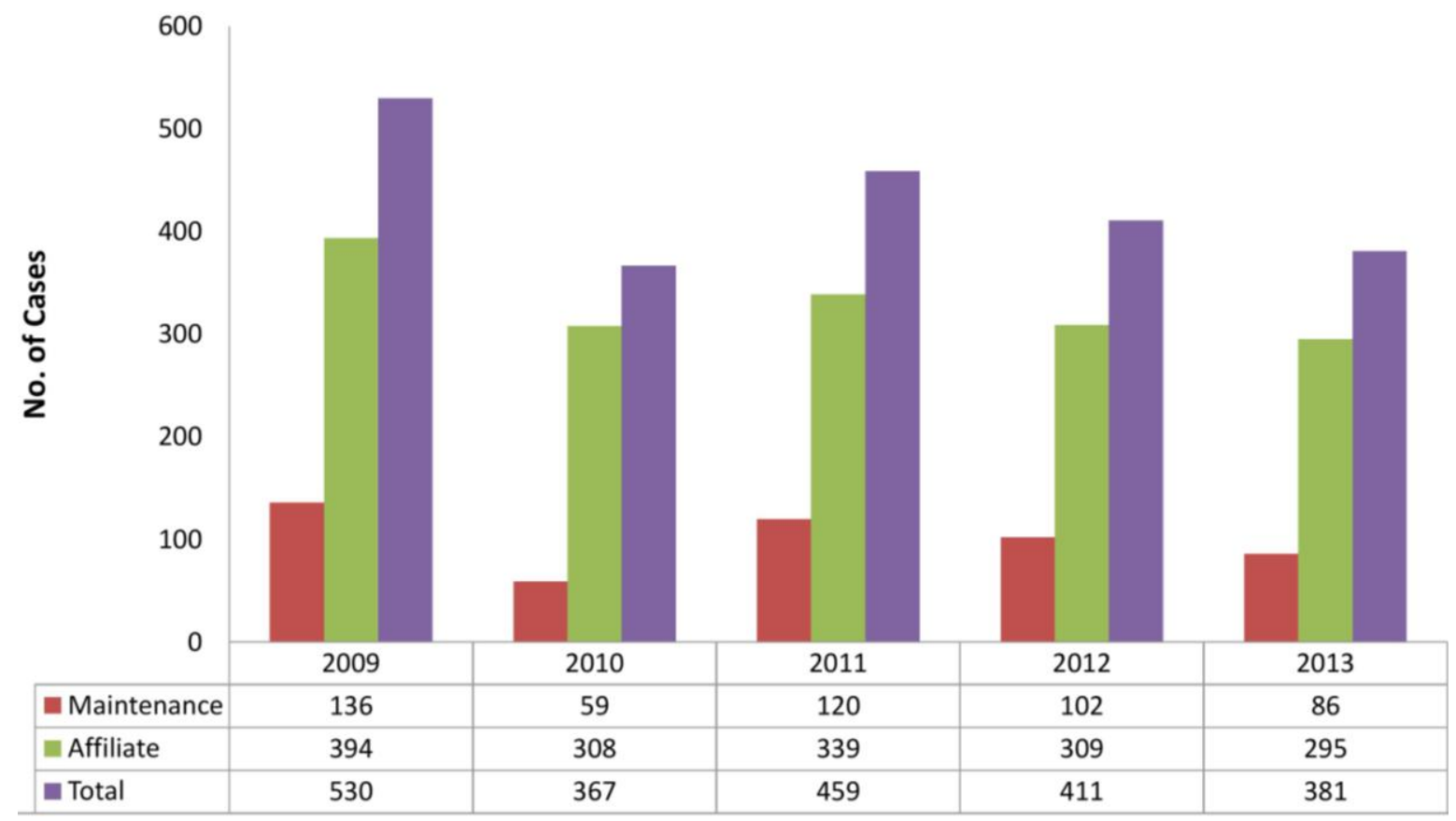

Figure 3. Urban child maintenance cases- New Amsterdam, Guyana

Source: Data extracted from Court Records, 2014

Looking at the rural/ urban data comparisons in Figure 2 and Figure 3 showed that there are a 
significantly lower number of child maintenance cases reaching the courts in the rural districts as against urban districts. Of a total of 1223 cases over the five year period, 218 or 17.8 percent were once married fathers in contrast to 1005 or 82.2 percent who were in non marital relationships. There are two possible explanations which may be drawn from this finding. First, that there may be more familial and community support in rural communities hence there is not a great need to seek maintenance from the court, and second the reluctance to pursue such actions so as not to rupture community solidarity. Consistent with earlier findings on child support and fathers who were once married, the data from rural communities also showed lower figures in contrast to fathers who were not married. On the other hand, data from the court in the urban district clearly showed an overall increase in child maintenance matters before the court. Of the 2148 cases, 503 or 23.4 percent were maintenance and 1645 or 76.6 percent were affiliate cases. These rural/urban trends are consistent for both fathers who were once married and those from non-marital relationships.

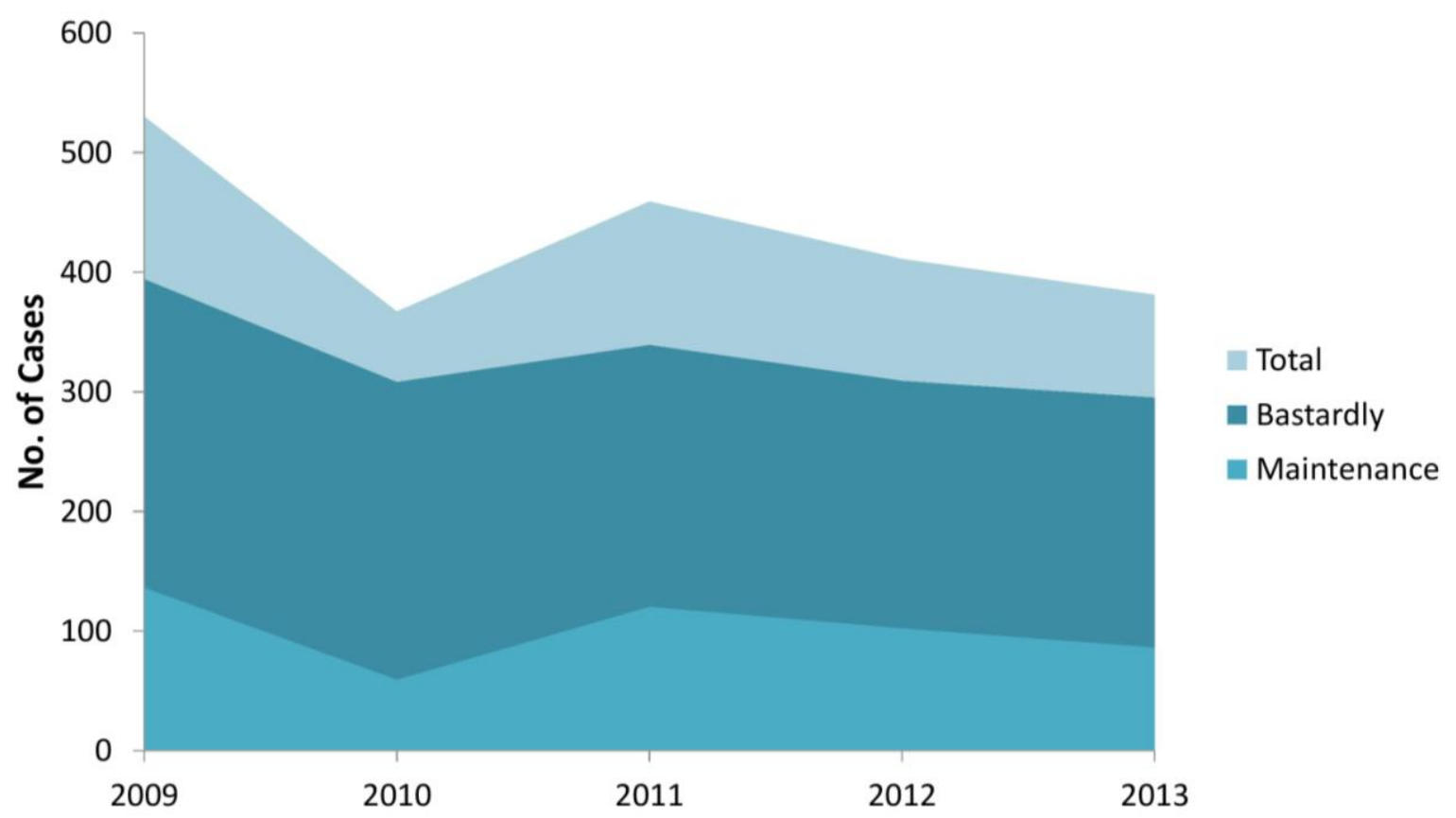

Figure 4. Trends in child maintenance cases in Berbice Court from 2009-2013 Source: Data extracted from Court Records, 2014

The overall trend as shown in Figure 4 which looks at the five year trend, cements the overall patterns of child maintenance matters for both affiliate (not married) fathers and those who were once married.

\subsection{Systemic Weaknesses in the Court}

Whilst the paper set out to find out the child maintenance and its impact on the quality of father child relationships, other issues which evolved pointed to the systemic weaknesses resulting in the lack of timely payment of child maintenance. This seemed to be directly linked to the introduction of the new two day rule which saw mothers spending long hours awaiting on signatures to uplift their maintenance cheques due to the introduction of the 
unannounced new two day rule. The effect of this change on female parents and by extension their family are captured in newspaper articles which have chronicled women stories. (See Box1) The unannounced imposition seems to be punitive to women and suggested that the situations of the child and custodial parent have not been considered since this directive meant that poor women, dependent on their child support had to either absent themselves from work, in cases where they were working, either getting official time off and/ lose pay due to them having to complete a sign up process on one day and then uplifting the cheque on the following day. This exercise in itself is both costly and punitive since low income women who are in need of this money to take care of their children's needs, may be forced to incur additional costs through borrowing. One of the mothers shared that due to her lack of knowledge on the new process, she was forced to beg the other poor mothers to assist her with the transportation costs to return home (Kaiteur News, 2012).

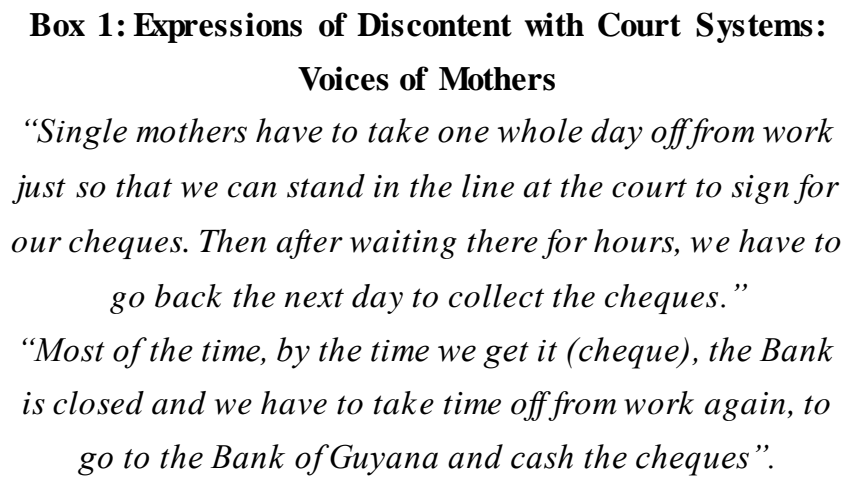

\subsection{Adequacy of Child Maintenance and Ability to Pay}

Despite the limited amount of work on the actual impact of child support on economic well-being, a sizable amount of research suggests that an optimal child support system could yield substantial gains to custodial families (Bartfeld, 2000). Definitely mothers, particularly single mothers need the support for the child's well being. The Act (Cap 45:03)) stipulates that child support fees can range from as low as GYD 1500 (USD 7.50) a week to GYD 3000 (USD15.00) and may extend up to GYD 25000 (USD 125.00) monthly. These are all situational and subjective and rely heavily on the individual Magistrate since the Magistrate has the authority to determine a payment cost which is considered reasonable based on the father's income and other child care and family commitments. Despite the forgoing, 24 or 80 percent of the fathers indicated, that the child support payment is inadequate.

Notwithstanding the inadequacy of the child maintenance cited by the large majority of fathers, 9 or 30 percent of the fathers expressed that they sometimes found it difficult to meet this financial commitment. The reasons cited included unemployment or underemployment and other family commitments coupled with a high cost of living.

\subsection{Child Maintenance and Visitation}

Visitation could be negatively tied to child maintenance with the father only being allowed to visit with the child based on him meeting his financial obligations. The challenge to this 
however, is whether monies should be primary factor in determining the relationship between father and child. Children should be able to enjoy a relationship with both parents and fathers ought to be able to play a meaningful role in the life of their child at every developmental stage.

Like visitation, the study found that many fathers were not satisfied with the time spent with their children. The outcomes of maintenance matters in terms of child support and visitation are oftentimes dependent on the individual magistrate rather than a systemic process employed by other countries to determine the outcomes. Male attitudes in Court, it is felt (Note 1) often affect their outcomes since it is perceived that men do not often speak up in Courts and may rarely address issues of visitation. Probation officers are usually in court and matters may be referred to ensure that visitation is addressed if it becomes an is sue but this is not institutionalized and is again very subjective.

Most of the fathers in the study adopted the "wait and see" (Note 2) attitude. The findings suggest that 27 or 90 percent of fathers seem to take the line of least resistance, and whilst maintaining that they would wish more time with child, this does not correlate with them aggressively seeking joint custody or more visitation rights. It seems that they are satisfied with a minimal role in the life of their child through their Court payment since, except for one father, none of the others expressed an interest in fighting for more custody and visitation. Father justified their "contact avoidance" stance in not aggressively pursuing visitation claiming the need to avoid conflict with the child's mother and not wanting to get into trouble or in conflict with the former spouse or the law. This further corroborates the view posited by Wright and Price (1986) who addressed the notion of avoidance where fathers stay away to avoid reminders of their "lost" child and conflict with an estranged partner.

\subsection{Father Child Relationship: What Fathers Say?}

The research sought to garner the perceptions of fathers satisfaction with their relationship with their child despite being absent from their child's lives. Fathers' satisfaction with the relationship with their children was measured by their responses to four questions. The first asked if they were satisfied with amount of time spent with child/children, whilst the second asked if they missed their child and the third sought to garner their perception on whether they felt that the child misses them with the final question asking fathers to describe their relationship with their child.

The various trends running through the data suggest that men would want to have a more active role in their children's lives and are not satisfied with their relationship. Except for 2 or 6.7 percent, all of the other fathers ( 28 or 93.3 percent) stated that they were not satisfied with the relationship they have with their children and missed their children. Even when they had time with the children it was not always adequate. Many fathers (18 or 60 percent) felt that their children also missed them but were not in a position to do better. One father indicated that even when he could not have visited, the child was encouraged to call and the mother has since denied both himself and the child this opportunity to maintain their relationship. Thirty percent (9) of the fathers stated that there was no relationship at all other than their court payment. Fathers' lack of involvement in their children's life is affected either by geographic 
location, relationship with their child's mother and the new families created by either parent. Other contributory factors which affected fathers were their family of origin since 12 or 40 percent of those who indicated that they had not grown up with their own fathers were concerned that their children would suffer from the emotional loss that they experienced as children. Fathers also expressed their concerns about their absence from the lives of their children. A few excerpts are captured below:

"I grew up without a father from age 10 and I know how I used to feel because my father was not there. My son is young, the court has given me two hours twice a week and even that is a lot of drama. We are in court and I am fighting to see my child, for me it is not about the money men should support financially, it's about my relationship with my son"

"I work away from the area where my child lives and after my relationship with my child's mother ended and I formed another relationship; my child mother got vicious and I don't really have a relationship with my child. This makes me feel bad since a boy needs his father even when their parents are no longer together. Sometimes it is tough to meet the Court payment but it is my responsibility to support my son. I hope that we can build a relationship when he gets older but that might be tough."

"I used to have a good relationship with my son but that changed after his mother banned him from calling me. The money I pay at the Court is not enough to maintain him but if he asks me for anything I give it to him but I stay away because of his mother and because of my new family-for peace sake."

"It hurts not getting enough time with my child....it hurts"

"The court can do more to see that fathers stay involved and get to see their children, the court favours women"

\subsection{Father Relationship with Mother of Child}

The findings corroborate the work of other researchers in the field since a large majority of the fathers contend that their relationship with their child is affected by the quality of the relationships they have with the mothers of their children. Very few fathers described having a good relationship with the mother of their child. Except for 2 fathers (6.7 percent), the large majority 28 or 93.3 percent of those interviewed ind icated that their relationship with the mother of the child was very poor or non-existent. This was evident despite the length of separation. One father indicated that his child's mother was "vicious and spiteful" since he would like his son to meet and blend into his new family but this is strongly rejected by the child mother. Angry parents contribute to angry children thereby continuing the cycle of dysfunctional children, parents and families. Children may be angered by thinking that their father may have left them because they do not care. Additionally, some fathers ( 24 or 80 percent) of the fathers interviewed expressed the hope that as the children get older they will understand the reasons why their role was minimal in their life.

\subsection{Father Responsibilities and Mechanisms for Addressing Defaulting Fathers}

In seeking to ascertain how fathers perceived their responsibilities as a provider for their child, they were asked to state how they felt about paying through the Court. Mixed reactions were 
garnered. Reactions such as, "ashamed and hurtful", "this was done to spite me", "very upset and hurt", "sad because I did not want the relationship with my wife nor child to end". One father also stated that he felt especially sad since he had already been supporting his child and could have "done this outside the court" however he was of the opinion that his child mother wanted to publicly humiliate him after he had moved on.

The study sought to ascertain from fathers how non-payment of child support should be addressed. According to the law, if fathers cannot afford to pay and are derelict in their duties, they should face the full brunt of the law and be sent to prison. Some fathers upheld this view ( 4 or 13.3 percent) whilst the others 26 or ( 86.7 percent) felt that imprisoning defaulting fathers should be a last resort and a new system should be devised to track men who are employed and enforce deductions from their salaries.

In providing additional views on this issue, the findings showed that 21 or 70 percent of fathers felt that every situation should be addressed based on the individual context of fathers especially since the primary issues facing men were linked to either unemployment and/or underemployment. Fathers' non-payment cannot be isolated from poverty and their general financial circumstances. Thus whilst fathers should be made to undertake their responsibilities, the reality is that every option should be exercised to ensure that they can do so especially in the context of Guyana where almost half of the population lives below the poverty line. Although the 1999 Household Income and Expenditure Survey indicated a marked reduction in poverty since 1993, the incidence of poverty in Guyana is still unacceptably high. The survey revealed that 36.4 percent of the population in Guyana lives in absolute poverty, and 19.1 percent exist in a state of critical poverty (Guyana, National Development Strategy, 2001). It must also be noted that the Five Year Strategic Action Plan of the Guyana Women and Gender Equality Commission states that women are more likely to be living in poverty, and increasingly carry sole responsibility for household maintenance and childrearing; women are in lower paying jobs and less likely to be in decision-making positions (Women and Gender Equality Commission, 2013).

Nonetheless, if more than one third of the country is living in poverty and about 19 percent live in absolute poverty, it means that many of the fathers summoned for child support may be living in poverty. Therefore if fathers are sent to prison no one really benefits. The reality is that tax payers will have to maintain the father in prison even as the child and family are still deprived of an income. When fathers are released from their prison term they are still expected to make all payments inclusive of those missed during the period of incarceration. If the factors that prohibit fathers' nonpayment are not duly considered then the cycle continues and the child continues to be affected. Fathers should have a medium for discussion which could be either the Court, the child's mother or a Probation Officer. An institutionalized accountability medium either working via the Court of the Probation and Social Services Department which allows the father to sort out his financial situation until he can do better will assist both the father and the child and the family to build a relationship that benefits the child. A child growing up without a father may be angered by the lack of support from this significant parent. Social security measures in cases deemed necessary demonstrate national and community responsibility in child well being. This however must be done within an 
institutionalized framework which tracks and responds to the payment patterns of fathers and support them when it has been assessed that their circumstances would have forced them to be in default. This system is not about protecting fathers, but working with fathers in the best interest of the child and demonstrates a strong sense of commitment to child well being.

\section{Conclusions}

This research has shown that even when fathers pay child maintenance it does not necessarily improve their relationships with their children. There is no doubt that both parents have a financial responsibility for their children. Moreover, missing fathers affect the well being of children in two ways, firstly when they are not present to see them go through the changing periods of their lives and make meaningful contributions to their overall growth and development and secondly where they suffer deprivations in the home when fathers do not contribute financially. This continued lack of father involvement in the lives of their children can negatively impact the overall well being with the child.

In an economy where a significant portion of women are single parents and work in low income jobs, they need all available resources inclusive of the monies from the child support to upkeep their family. The withholding of monies needed to maintain the child negatively affects the well being of the child and family. The reality is that some fathers for different reasons mostly tied to their economic situation, may be unable to pay. An institutionalized mechanism to which the Court has access is needed to ascertain the mitigating factors that prevent fathers from providing support. Whilst the Court has a responsibility to use the law to punish fathers who do not pay, sending the father to prison means that the child still suffers and taxpayers will be maintaining the father who is incarcerated. This can foster further anger against the child and the child's mother and can also contribute to dysfunctional children. Social security measures are needed to cushion the impact of father's nonpayment on the child since the best interests of the child must be paramount.

Whilst some may argue that child maintenance and visitation are two separate issues they should not be separated. Based on their perception of their view of the Court system seeming to be more favourable to women, fathers do not assertively pursue their care giving role which visitation can foster rather they seem to see the provider role as doing their duty even though expressing concerns about the impact of their absence on the child's well being. Visitation should be institutionalized and factored into child maintenance arrangements and monitored by child protection officers so that these arrangements operate on best interest principle. Parents should be encouraged to see the beneficial aspect of father child relationships and its importance to the child's wellbeing.

\section{References}

Amato, P. R. (1987). Family Processes in One-Parent, Stepparent, and Intact Families: The Child's Point of View. Journal of Marriage and Family, National Council on Family Relations, 49(2), 327-337. http://dx.doi.org/10.2307/352303

Arditti, J. A., \& Keith, T. Z. (1993). Visitation Frequency, Child Support Payment, and the Father-Child Relationship Post-divorce. Journal of Marriage and Family, National Council 
on Family Relations, 55(3), 699-712. http://dx.doi.org/10.2307/353350

Bartfeld. J. (2000). Child Support and the Postdivorce Economic Well-Being of Mothers, Fathers, and Children. Demography, Springer: Population Association of America, 37(2), 203-213. [Online] Available: http://www.jstor.org/stable/2648122

Camfield et al. (2008). Children's Well Being in contexts of Poverty: Approaches to Research Monitoring and Participation. Young Lives Technical Note (No. 12): Child Support Assessments. [Online] Available: http://www.humanservices.gov.au/customer/services/child -support/child-support-assessment

Government of Guyana. (2011). Contributions to the OHCHR Study on Children Working and/or Living on the Streets.

Guyana Chronicle. (n.d.). Go after the child fathers. [Online] Available: http:/guyanachronicle.com/go-after-the-child-fathers/

Henry, P. (2014). A Child Protection Mapping and Assessment Report. Draft report prepared for UNICEF and the Child Protection Agency/MLHSSS, Guyana.

Kaieteur News. (2012). Collecting child support money a "three days running"- frustrated mothers. [Online] Available: http://www.kaieteurnewsonline.com/2012/12/08/collecting-child -support-money-a-three-days-running-frustrated-mothers/

Legal Aid. Child Maintenance: The Law and You. [Online] Available: http://www.legalaid.org.gy/files/gaw1/030_lawandyou_law.pdf

Mc Dowel, Z. (2000). Elements of Child Law in the Commonwealth Caribbean. University of the West Indies Press.

NEF. (2009). A guide to measuring children's well-being. [Online] Available: http://www.neweconomics.org/publications/entry/a-guide-to-measuring-childrens-well-being

OECD. (2009). Gender and Sustainable Development: Maximising the Economic, Social and Environmental Role of Women. [Online] Available: http://www.oecd.org/social/40881538.pdf

Osborne. (2003). The Maintenance Act: Is it working? Stabroek News. [Online] Available: http://www.landofsixpeoples.com/

Peterson, J. L., \& Zill, N. (1986). Marital Disruption, Parent-Child Relationships, and Behavior Problems in Children. Journal of Marriage and Family. National Council on Family Relations, 48(2), 295-307. http://dx.doi.org/10.2307/352397

Seltzer, J. A. (1991). Relationships between Fathers and Children Who Live Apart: The Father's Role after Separation. Journal of Marriage and Family, National Council on Family Relations, 53(1), 79-101. http://dx.doi.org/10.2307/353135

Statham \& Chase. (n.d.). Child Well Being: A Brief Overview. Child Well Being Research Centre.

Statham, J., \& Chase, E. (2010). Childhood Wellbeing Research Centre. BRIEFING PAPER 1 


\section{Macrothink}

Issues in Social Science

ISSN 2329-521X 2015, Vol. 3, No. 2

August 2010 Childhood Wellbeing: A brief overview. [Online] Available: https ://www.gov.uk/go vernment/uploads/system/uploads/attachment_data/file/183197/ChildWellbeing-Brief.pdf

Thompson, A. R. (1994). The Role of the Father After Divorce. Children and Divorce. Spring, 4(1), 210-235. Princeton University. http://dx.doi.org/10.2307/1602485

UN Women Watch: Directory of UN Resources on Gender and Women's Issues. [Online] Available: http $/ /$ www.un.org/womenwatch/directory/women_and_poverty_3001.htm

Wollny, I., Apps, J. \& Henricson, C. (2010). Can governments measure child well being? London: Parenting Institute.

\section{Notes}

Note 1. Fathers according to Magistrate interviewed do not speak up in court and resultantly the woman who articulates her situation will get the ear of the Court.

Note 2. The type of attitude where the father prefers to wait and see if the mother's attitude will change or that the child will grow up and look for them thereby allowing for a relationship when the child gets older. 